\title{
Nutritional Status of Pre-School Children of Pokhara- Lekhanath Metropolis, Kaski
}

Gyanendra Raj Poudel*

\begin{abstract}
The study is aimed at finding out the nutritional status of pre-school children with relation to occupation, annual income and education status of their parents. The study is based on descriptive research design. Weight for height, height for age, and weight for age were the main areas of nutritional status of children which were measured using primary data only. The study has been carried out in Ward no 9, 10 and 11 of Pokhara Lekhnath Metropolis, Kaski. There were 15 pre-schools in the study area. Among them, 6 pre-schools were taken by the convenient sampling method and from each pre-school 20 children were chosen by the lottery method. Their parents were also included in the population of the study. The study reveals that the majority of the respondents are engaged in different services in Nepal and the nutritional status of their children was found better than Nepal's national nutritional standard. The children, whose parents have yearly income of 2 to more than 6 lakhs, have better nutritional status. Likewise, in this study, not a single mother is illiterate; it has been revealed that the mother's educational standard is the reason behind children's poor nutritional status.
\end{abstract}

Key Words: under weight, wasting, weight for age, weight for height.

\section{Introduction}

Nutrition is the sum total of the processes involved in the taking in and the utilization of food substances by which growth, repair and maintenance of the body are accomplished (Hrookoner, 2009). Nutritional status of our country is very poor. Nutrition is most important for children because it is directly linked to all aspects of their growth and development factors which have direct ties to their health status as adults. Pre-school children are more vulnerable to this case because of their high nutritional needs for growth and development. Nutrient requirements of different groups of population are influenced by age, sex, physical activities, physiological status, and environmental factor (Bhandari \& Chhetri, 2013). Moreover, number of factors, which affect acceptability and the utility of food, are also related to habit, availability of food, family members, cultural practices and knowledge about food's connection with health.

Sound nutrition can change children's lives, improve their physical and mental development, protect their health and lay a firm foundation for future productivity. Here, the main concerning subject is the pre-school going children for whom nutritious food is most important and the basic need. Maternal and child mortality have declined significantly in Nepal to the extent that Nepal is on track to meet the Millennium Development Goals for Maternal and Child Mortality (DOHS, 20132014). Similar improvements have not been seen in general nutrition status of them. Still under five year child mortality rate is 35.80 per thousand (NDP, 2017). Under five year children belong to preschool age children. The pre-school period is a time when children develop concepts and lifelong habits. Nutrition experience at a young age influences nutritional habits in adulthood (Timilsena, 2012). This means nutritional knowledge also contributes to developing habits.

The general health condition of the population of Nepal is poor. Particular concern is the ill health, retarded growth and disability found among helpless children, because of which every year plenty of children die in the world due to malnutrition and this number is larger in undeveloped and developing countries. Especially in the South Asian countries, nutritional status of children depends on various

* Lecturer, HPPE Department, PN Campus, Pokhara. 
factors such as health knowledge and practice of mother, occupation of parents, economic condition, infections disease, immunization (Mishra, 2009). So, the researcher has tried to find out the relation between nutritional status of pre-school children aged between 2-5 years and occupation, economic status and educational status of parents. The study area was purely urban. The study is supposed to reflect the nutritional status of pre-school children in Pokhara. It shall be helpful for the further researchers as well as the country's policy makers who are at the level of formulating policy to develop the human resources.

\section{Methods and procedures}

The study is based on a descriptive nature with analytical data focused on obtaining the information about the nutritional status of preschools children. The study area is PokharaLekhanath Metropolis, Kaski. There are 33 Wards and 70 pre-schools in this study area. Among them, 6 pre-schools are selected from the Ward no. 9, 10 and 11. 6 pre-school and Ward no.9, 10 and 11 have been taken by the use of convenience sampling method. From selected each pre-school, 20 children were chosen through lottery method of simple random sampling and their parents (either father or mother) are also included as sample of the study. Interview schedule form has been used to collect the data from the parents and observation, weighing scale and nonstretching measuring tape were used to get the information about weight and height of the selected children. Nutritional status of the children was assessed by anthropometric measurement.

\section{Result and discussion}

According to census 2011, literacy rate of Pokhara valley is 83 percent which indicates the people are well educated. Guardians have knowledge about health and nutrition of children but the condition of job, business and the other engagement of parents link to the children and their nutritional status .

\section{Nutritional status of children on the basis of occupation of parents}

Occupation is one of the main contributing factors of the nutritional status of the children which is also the main source of income. The following table shows the prevalence of wasting, stunting and under weight on the basis of occupation of the parents.

Table 1. Nutritional status of children on the basis of parent's occupation

\begin{tabular}{llrrrr}
\hline \multirow{2}{*}{ Measurement } & Nutritional Status & Service in Nepal (\%) & $\begin{array}{r}\text { Service in Foreign } \\
\text { countries (\%) }\end{array}$ & Business (\%) & If any (\%) \\
\hline \multirow{5}{*}{ Weight for Height } & Severe wasted & $4(3.33)$ & $2(1.67)$ & $2(1.67)$ & $3(2.5)$ \\
& Nasted & $8(6.67)$ & $2(1.67)$ & $6(5)$ & $2(1.67)$ \\
& Normal & $38(31.67)$ & $36(30)$ & $14(11.67)$ & $3(2.5)$ \\
& Total & $50(41.67)$ & $40(33.34)$ & $22(18.34)$ & $8(6.67)$ \\
& Severe stunted & $4(3.33)$ & $3(2.5)$ & $3(2.5)$ & $2(1.67)$ \\
Height for Age & Stunted & $5(4.17)$ & $5(4.17)$ & $6(5)$ & $5(4.17)$ \\
& Normal & $41(34.17)$ & $32(26.67)$ & $13(10.83)$ & $1(0.83)$ \\
& Total & $50(41.67)$ & $40(33.34)$ & $22(18.34)$ & $8(6.67)$ \\
& Severe & & & & $2(1.67)$ \\
& underweight & $2(1.67)$ & $1(0.83)$ & $2(1.67)$ & $2(1.67)$ \\
& Underweight & $6(4.17)$ & $2(1.67)$ & $4(3.33)$ & $2(13)$ \\
& Normal for Age & $42(35)$ & $37(30.83)$ & $16(13.33)$ & $4(3.33)$ \\
& Total & $50(41.67)$ & $40(33.33)$ & $22(18.34)$ & $8(6.67)$ \\
\hline
\end{tabular}

(c) 2018 HEAN 
The table 1 demonstrates that, among 120 respondents, 50 parents have been involved in different services in Nepal. Among their children, 3.33 percent, 6.67 percent and 31.67 percent children are found severely wasted, wasted and normal respectively. Likewise, 3.33 percent, 4.17 percent and 34.17 children are found severely stunted, stunted and normal, respectively. Similarly, 1.67 percent, 4.17 percent and 35 percent children are severely underweight, underweight and normal respectively.

Among 40 respondents who are engaged in foreign service, 1.67 percent 1.67 percent, and 30 percent are severe wasted, wasted and normal respectively. Two and half percent, 4.17 percent and 26.67 percent are severely stunted, stunted and normal, respectively and similarly, 0.83 percent, 1.67 percent and 30.83 percent are severely underweight, underweight and normal respectively.

Similarly, 22 respondents are involved in business. Among their children, 1.67 percent and 5 percent are severely wasted and wasted; 2.5 percent and 5 percent are severely stunted and stunted. Likewise 1.67 percent and 3.33 percent are severely underweight and underweight respectively. Rests of them are normal.

Among remaining 8 respondents, 2.5 percent and 1.67 percent children are severely wasted and wasted, 1.67 percent and 4.17 percent are severely stunted and stunted, and 1.67 percent and 1.67 percent children are severely underweight and underweight respectively. Rest of them are normal.

The study shows that the most of the children's nutritional status is normal. Thus the children, whose parents are in service in Nepal, are more wasted and underweight and the children, whose parents are in business, are stunted. The study area is urban area and one of the largest cities of the country. That's why most of the parents are involved in service in Nepal or foreign or business in Nepal. Among them, the children, whose parents are in foreign service, have better nutritional status.

\section{Nutrition status of children on the basis of income}

Good income helps to maintain good health. Low economic status cannot meet the nutritional need. The following table represents the status of wasting, stunting and underweight on the basis of annual income.

Table 2. Prevalence of nutrition status of children on the basis of parents' annual income

\begin{tabular}{clrrr}
\hline \multirow{2}{*}{ Measurement } & Nutritional Status & $\begin{array}{c}\text { 2-3 Lakhs } \\
(\%)\end{array}$ & $\begin{array}{c}\text { 3-6 Lakhs } \\
(\%)\end{array}$ & 6 Lakhs Above (\%) \\
\hline \multirow{5}{*}{ Weight for Height } & Severely wasted & $6(5)$ & $3(2.5)$ & $2(1.67)$ \\
& Wasted & $8(6.67)$ & $6(5)$ & $4(3.33)$ \\
& Normal & $19(15.83)$ & $20(16.67)$ & $52(43.33)$ \\
& Total & $33(27.5)$ & $29(24.17)$ & $58(48.33)$ \\
& Severely stunted & $4(3.33)$ & $5(4.17)$ & $3(2.5)$ \\
& Stunted & $10(8.33)$ & $7(5.83)$ & $4(3.33)$ \\
& Normal & $19(15.83)$ & $17(14.17)$ & $51(42.5)$ \\
& Total & $33(27.5)$ & $29(24.17)$ & $58(48.33)$ \\
& Severely underweight & $3(2.5)$ & $2(1.67)$ & $2(1.67)$ \\
& Underweight & $8(6.67)$ & $4(3.33)$ & $54(45)$ \\
& Normal & $22(18.33)$ & $23(19.67)$ & $58(48.33)$ \\
\hline
\end{tabular}


The above table 2 reveals that 5 percent and 6.67 percent children are severely wasted and wasted and 3.33 percent and 8.33 percent children are severely stunted and stunted. Likewise, 2.5 percent and 6.67 percent children, whose parents' annual income is 2-3 lakhs, are severely underweight and underweight respectively. Similarly, 2.5 percent and 5 percent children are found severely wasted and wasted, 4.17 percent and 5.83 percent children are severely stunted and stunted and 1.67 percent and 3.33 percent children, whose parents' income is 3-6 lakhs, are severely underweight and underweight respectively. Moreover, 1.67 and 3.33 percent children are severely wasted and wasted, 2.5 and 3.33 percent children are severely stunted and stunted, 1.67 and 1.67 percent children, whose parents income is 6 lakhs above, are severely underweight and underweight.
Yadav, Gupta, \& Shrestha (2011) reported that economic status is a strong predictor of the prevalence of malnutrition in the children. Children from the family of poor economic status are almost four times affected as much as the children from the rich economic status. The above table shows there are 3 categories of annual income i.e. 2-3 lakhs, 3-6 lakhs and more than 6 lakhs of respondents parents. The result shows that if parents have high income, the nutritional status of the children is relatively is better.

\section{Prevalence of nutritional status of children on the basis of mother's education}

Mother's education is the major factor that directly affects to the nutritional status of children. The following table represents the prevalence of wasting, stunting and underweight on the basis of mother's education.

Table 3. Prevalence of nutritional status of children on the basis of mother's education

\begin{tabular}{llrrr|}
\hline Measurement & Nutritional Status & $\begin{array}{r}\text { School Level } \\
\text { Education (\%) }\end{array}$ & $\begin{array}{c}\text { Higher Secondary } \\
\text { Level (\%) }\end{array}$ & $\begin{array}{r}\text { Higher Secondary } \\
\text { Level above (\%) }\end{array}$ \\
\hline \multirow{3}{*}{ Weight for } & Severely Wasted & $8(6.67)$ & $2(1.67)$ & $1(0.83)$ \\
Height & Wasted & $7(5.83)$ & $8(6.67)$ & $3(2.5)$ \\
& Normal & $42(35)$ & $26(21.67)$ & $23(19.17)$ \\
Height for Age & Total & $57(47.5)$ & $36(30)$ & $27(22.5)$ \\
& Severely Stunted & $6(5)$ & $3(2.5)$ & $3(2.5)$ \\
& Stunted & $10(8.33)$ & $7(5.83)$ & $4(3.33)$ \\
& Normal & $41(34.17)$ & $26(21.67)$ & $20(16.67)$ \\
Weight for Age & Total & $57(47.5)$ & $36(30)$ & $27(22.5)$ \\
& Severely Underweight & $3(2.5)$ & $2(1.67)$ & $2(1.67)$ \\
& Underweight & $6(5)$ & $4(3.33)$ & $4(3.33)$ \\
& Normal & $48(40)$ & $30(25)$ & $21(17.5)$ \\
& Total & $57(47.5)$ & $36(30)$ & $27(22.5)$ \\
\hline
\end{tabular}

The table 3 shows that 57 respondent parents have school level education. Among their

children, 6.67 percent and 5.83 percent are severely wasted and wasted, 5 percent and 8.33 percent children are severely stunted and stunted and 2.5 percent and 5 percent children are severely underweight and underweight respectively.
Among the children of 36 respondent parents who passed higher secondary level, 1.67 percent and 6.67 percent children are severely wasted and wasted, 2.5 percent and 5.83 percent children are severely stunted and stunted and 1.67 percent and 3.33 percent children are severely underweight and underweight. 
Among the children of 27 respondent parents who passed higher secondary level and above, 0.83 percent and 2.5 percent are severely wasted and wasted, 2.5 percent and 3.33 percent children are severely stunted and stunted and 1.67 percent and 3.33 percent children are severely underweight and underweight .

Nepal Demography and Health Survey 2011 has reported that children, whose parents are illiterate and who only have primary level education, are more stunted, wasted and underweight. In this study area, all children's mothers are literate. The above result shows if the mothers have higher education the nutritional status of children is found better except wasted and stunted in school level and higher secondary. Therefore, the educational level of mother is a strong factor in determining the health status of children.

\section{Conclusion}

On the basis of the above findings, it can be concluded that most of the parents are involved in other occupations rather than agriculture and it helps to increase the nutritional status of children. Likewise, 48.33 percent of respondent's parents earn more than 6 lakhs per year and their children nutritional status seems better. This study also reveals that the children, whose mothers have school level education, are more affected from malnutrition. So, it can be concluded that the education of mothers is the major cause to determine the nutritional status of their children. It is also concluded that the nutritional status of pre-school children aged 2-5 years of the study area is better than the national data.

\section{REFERENCES}

Bhandari, T.R. \& Chhetri, M. (2013). Nutritional status of under five year children and factors associated in Kapilvastu District Nepal. Journal of Nutrition Health Food Science 1 (1);6.

DOHS. (2013-2014). Nepal-Annual report of department of health services. Yearly Report.

Mishra, S.K., Bastola, S.P. \& Jha, B. (2009). Biochemical nutritional indicators in children with protein energy malnutrition attending Kanti Children Hospital. Institute of Medicine. Vol. 7, No. 2, Issues 26, (pp. 129-134).

NDHS. (2011). Nepal demographic and health survey. retrieved from http://www.moh.gov. np/english/publicaiton/NDHS\%202011\%20 full\%20version.pdf.

NDP. (2017). Nepal Demographics Profile. https:www.indexmundi.com/Nepal/ demographics-profile.html. Retrieved from 9/1/2017

Timilsina, P. (2012). A study on nutritional status of under five year children in hemja VDC kaski. Unpublished Master Degree Thesis Submitted to HPPE Department, P.N. Campus, Pokhara.

Yadav, D.K., Gupta, N. \& Shrestha, N. (2011). An assessment of nutritional status of children less than 3 years in rural area of mahhotari district of Nepal. International Journal of Medical Research and Health Science 2014; 3 (3): (pp. 597-603 ). 